\section{Terrestrial carbon storage at the LGM}

SIR - Several studies have yielded discrepant estimates for the change in carbon storage from the Last Glacial Maximum (LGM) to pre-industrial times which range widely from $\sim 0$ to $+1,350 \mathrm{Pg}$ (1 $\mathrm{Pg}=10^{15} \mathrm{~g}$ ) (refs $\left.1-6\right)$.

Two recent advances now permit a more rigorous evaluation of the available estimates of change in terrestrial carbon storage using the change in whole ocean $\delta^{13} \mathrm{C}$ value from LGM to pre-industrial times $^{6}$ : (1) the $\delta^{13} \mathrm{C}$ value of atmospheric carbon dioxide is known to have been $0.3-0.7 \%$ lower than present during the LGM (see ref. 7); and (2) it is possible to estimate the bulk $\delta^{13} \mathrm{C}$ value of carbon in pre-industrial biomass. From this information it is possible to calculate what the $\delta^{13} \mathrm{C}$ value of terrestrial biomass at the LGM would have to be in order to satisfy the mass/isotope balance for a specified change in carbon storage (see figure).

The $\delta^{13} \mathrm{C}$ value of carbon in preindustrial terrestrial biomass can be estimated in two ways. The first is based on over 250 carbon-isotope published ${ }^{8}$ and unpublished analyses of surface soils from C3 biomes spanning latitudes from $0-60^{\circ}$ and $4,600 \mathrm{~m}$ of altitude. The $\delta^{13} \mathrm{C}$ values of surface soils in those biomes in which $\mathrm{C} 4$ species are present are more difficult to constrain, but can be specified within broad limits from published soil $\delta^{13} \mathrm{C}$ values. This approach suggests that the isotope composition of carbon in the pre-industrial terrestrial biosphere $\left(\delta^{13} C_{b}\right)$ had a value of not less than $-25 \%$, using the range of available estimates for modern carbon storage in each of the major biomes ${ }^{1-5}$. An alternative modelling approach based on physiological considerations ${ }^{9}$ yields a bulk $\delta^{13} \mathrm{C}$ value of not higher than $-22 \%$ for carbon in pre-industrial terrestrial biomass.

The curves in the figure depict the relationship between change in carbon storage from the LGM to pre-industrial times $\left(m_{\mathrm{b}}-m_{\mathrm{b}^{\prime}}\right)$ and the carbon-isotope composition required for carbon in terrestrial biomass at the $\operatorname{LGM}\left(\delta^{13} C_{b^{\prime}}\right)$ to balance a whole-ocean $\delta^{13} \mathrm{C}$ value of $-0.32 \%$ o (for $\delta^{13} C_{b}=-22$ to $-25 \%$ ). It is immediately apparent that the high estimate of Adams et al. ${ }^{2}(1,350 \mathrm{Pg})$ is implausible as it would require that the $\delta^{13} \mathrm{C}$ value of the terrestrial biosphere be $\sim-50 \%$ at the LGM. The remaining published estimates yield more reasonable values, so to narrow the field further it is necessary to make an estimate of the difference in $\delta^{13} \mathrm{C}$ value of carbon in terrestrial biomass between LGM and pre-industrial times.
Using the estimates for $\delta^{13} \mathrm{C}_{\mathrm{b}}$ (discussed above), the $\delta^{13} \mathrm{C}$ value of the LGM atmosphere and incorporating the possibility that isotope discrimination in $\mathrm{C} 3$ plants was reduced at the $\mathrm{LGM}^{10}$, it is possible to estimate the difference in the bulk $\delta^{13} \mathrm{C}$ value of carbon in the terrestrial biosphere at the LGM relative to preindustrial times using the published biome distributions at the $\mathrm{LGM}^{1-5}$. Such a calculation suggests that the bulk $\delta^{13} \mathrm{C}$ value of carbon in the terrestrial biosphere at the LGM was $0-2 \%$ enriched in ${ }^{13} \mathrm{C}$ relative to the pre-industrial biosphere.

The range of changes in carbon storage which satisfy the mass balance considerations is $310-550 \mathrm{Pg}$ for a $\delta^{13} \mathrm{C}_{\mathrm{b}}$ of $-25 \%$ to $-22 \%$. From these estimates it can be seen that the low estimate of Prentice and Fung ${ }^{1}$ cannot be correct, as their estimate would require a pre-industrial versus LGM difference in the $\delta^{13} \mathrm{C}$ value of terrestrial carbon of over $5 \%$ to satisfy the mass balance. If it is assumed that the true value of $\delta^{13} C_{o^{\prime}}$ is not precisely known to be $-0.32 \%$, but can be expected to lie between -0.3 and $-0.4 \%$, then the range of permissible changes in carbon storage increases to $270-720 \mathrm{Pg}$, still precluding the highest and lowest published estimates. This range is similar to that of Prentice et al..$^{5}$ and Friedlingstein et al. ${ }^{3}$, and overlaps the lower end of the range cited by Van Campo et al. ${ }^{4}$.

The 'true' change in terrestrial carbon storage probably lies towards the lower end of the range given above, because (1) $\mathrm{C} 4$ species are at a competitive advantage at low $p \mathrm{CO}_{2}$ values and therefore may

1. Prentice, K. C. \& Fung, I. Y Nature 346, 48-51 (1990)

2. Adams, J. M. et al. Nature 348, 711-714 (1990)

3. Friedlingstein, P. etal. Geophys. res. Lett. 19, 897-900 (1992)

4. Van Campo, E., Guiot, J.\& Peng, C. Global planet. Change 8, 189-201 (1993)

5. Prentice, 1. C. et al. Globl Ecol. Biogeogr. Lett. (in the press).

6. Crowley, T. J. Nature 352, 575-576 (1991).

7. Leuenberger, M., Siegenthaler, U. \& Langway, C. C. Nature 357, 448-490 (1992)

8. Bird, M. I., Haberle, S. \& Chivas, A. R. Globl Biogeochem. Cycles 8, 13-22 (1994)

9. Lloyd, J. J. \& Farquhar, G. D. Oecologia (in the press)

10. Van de Water, P. K et al. Science 264, 239-243 (1994).

11. Cole, D. R. \& Monger, H. C. Nature 368, 533-536 (1994).

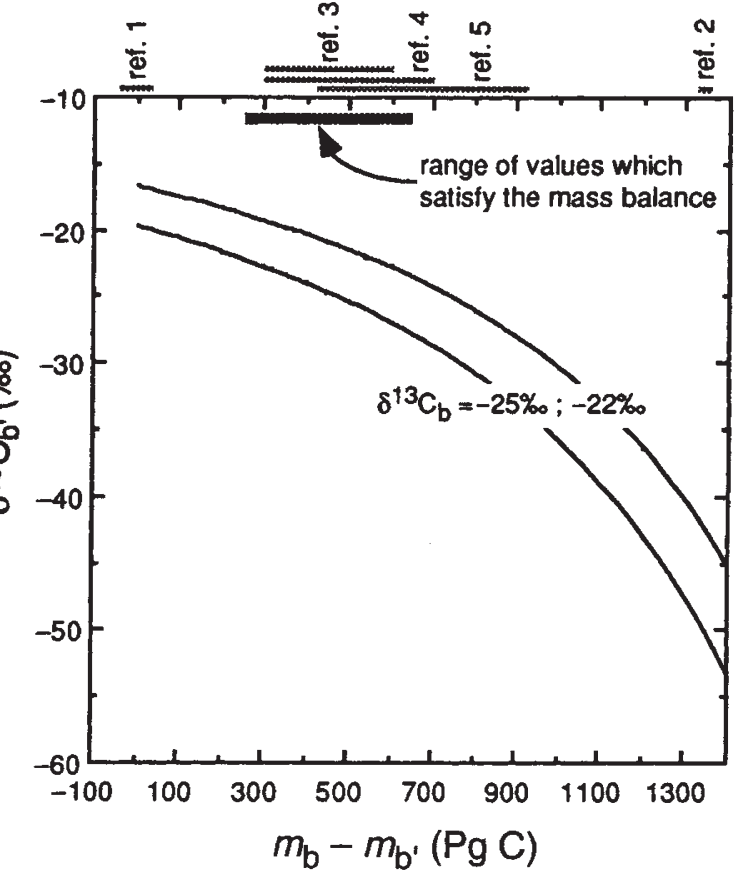

aiculated $\delta^{13} \mathrm{C}$ value of carbon in the terrestrial biosphere at LGM $\left(\delta_{b^{\prime}}\right)$ required to satisfy the mass balance the following equation:

$\delta_{\mathrm{b}^{\prime}}=\left[\delta_{\mathrm{a}} m_{\mathrm{a}}+\delta_{\mathrm{b}} m_{\mathrm{b}}+\delta_{\mathrm{o}} m_{\mathrm{o}}-\delta_{\mathrm{a}^{\prime}} m_{\mathrm{a}^{\prime}}-\delta_{\mathrm{o}^{\prime}}\left(m_{\mathrm{o}}+\left(m_{\mathrm{a}}-m_{\mathrm{a}^{\prime}}\right)+\right.\right.$ $\left.\left.\left(m_{\mathrm{b}}-m_{\mathrm{b}}\right)\right)\right] / m_{\mathrm{b}}$

where: $\delta_{a}=\delta^{13} \mathrm{C}$ value of carbon dioxide in pre-industrial mosphere $(-6.5 \%) ; m_{a}=$ mass of carbon in pre-industrial $m_{0}=$ mass of carbon in pre-industrial oceanic carbon (38,000 Pg); $\delta_{b^{\prime}}=\delta^{13} \mathrm{C}$ value of carbon in LGM GM terrestrial biosphere; $\delta_{a^{\prime}}=\delta^{13} \mathrm{C}$ value of carbon dioxide LGM atmosphere $(-7.0 \pm 0.2 \%) ; m_{a^{\prime}}=$ mass of carbon in $M$ atmosphere $(430 \mathrm{Pg}) ; \delta_{\mathrm{o}^{\prime}}=\delta^{13} \mathrm{C}$ value of oceanic carbon enoir at LGM $(-0.32 \% 0) ; m_{0^{\prime}}=m_{0}+\left(m_{\mathrm{a}}-m_{\mathrm{a}^{\prime}}\right)+\left(m_{\mathrm{b}}-m_{\mathrm{b}^{\prime}}\right)=$ ass of oceanic carbon reservoir at LGM. Note: the range for ef. 3 includes $100-300 \mathrm{Pg}$ peat accumulation ${ }^{5}$

have made up a larger proportion of biomass in any given biome at the LGM ${ }^{11}$; and (2) the mass balance approach used here does not include the possibility that low- ${ }^{13} \mathrm{C}$ carbon of marine origin may have been sequestered on the continental shelves during post-glacial sea-level rise ${ }^{6}$. Nevertheless, the isotope mass balance approach applied here does go a considerable way to narrowing the range of plausible estimates for changes in carbon storage from the LGM to the present, and is in substantial agreement with several of the previously published estimates.

Michael I. Bird

Research School of Earth Sciences,

Jon Lloyd

Graham D. Farquhar

Research School of Biological Sciences, Australian National University,

Canberra, ACT 0200,

Australia 